\title{
"How to Go On": Intersubjectivity and Progressivity in the Communication of a Child with Autism
}

\author{
Laura Sterponi \\ Alessandra Fasulo
}

\begin{abstract}
Through the lens of a case study of the spontaneous verbal interaction of a five-year-and-ten-month-old child with autism, this article offers a reflection on the psychological and epistemological underpinnings of human communication. In particular, in the analysis of verbal exchanges between a child with autism and his caregivers, we discuss formulaic talk and verbal play and the relation of these with sequential progressivity, expressions of personal stance, and intersubjectivity. The analysis allows us to unearth the inherent precariousness and unpredictability of communication and how it is perpetually vulnerable to failure. We suggest that the intrinsic risk of breakdown in intersubjectivity cannot be conceived of as a threat to successful communication, but rather, as an attribute of sequence progressivity and an essential component of communication as encounter with the other, grounded on mutual trust. [autism, intersubjectivity, sequence progressivity, trust]
\end{abstract}

Since 1943, when Leo Kanner published on the syndrome, up to the latest nosological description in the Diagnostic and Statistical Manual of Mental Disorders ([DSM-IV-TR], American Psychiatric Association 2000), autism has been defined as a developmental disorder that affects social interaction and communication. ${ }^{1}$ The Austrian psychiatrist identified as the outstanding characteristics of autism "the children's inability to relate themselves in the ordinary way to people and situations" (Kanner 1943:242, emphasis in original), that is an "extreme aloneness from the very beginning of life, not responding to anything that comes to them from the outside world" (Kanner 1943:248). According to Kanner, this pathognomonic feature was characteristically expressed in the child's failure "to assume an anticipatory posture upon being picked up" and "to adjust the body to that of the person holding him" (Kanner 1943:249). The DSM-IV-TR diagnostic criteria echo Kanner's characterization in that they include "marked impairments in the use of multiple nonverbal behaviors such as eye-to-eye gaze, facial expression, body posture, and gestures to regulate social interaction." In addition, the DSM-IV-TR definition includes "a lack of spontaneous seeking to share enjoyment, interests, or achievements with other people" and "lack of social or emotional reciprocity" as distinctive of autistic disorder.

Autism is also characteristically related to impaired communication. Kanner wrote that language is "deflected in a considerable measure to a self-sufficient, semantically and conversationally valueless or grossly distorted memory exercise" (Kanner 1943:243). He noted that children with autism repeated words and sentences in parrotlike fashion, 
producing immediate or delayed echolalic utterances with no personal connotation or communicative intention. Similarly, the DSM-IV-TR notes "marked impairment in the ability to initiate or sustain a conversation with others" and "stereotyped and repetitive use of language or idiosyncratic language."

These prototypical characterizations assume normativity in the ways people conduct social and communicative exchanges, and they portray individuals affected by autism as outside those norms. In this way the autistic condition comes to mark the boundaries of what we regard as human sociability and communication. As we argue in this article, such a delineation fails to recognize that mundane communicative interaction is punctuated by departures from normativity and that those departures not only do not break down communication but also are often the measure of felicitous interpersonal exchanges. The present case study of the spontaneous verbal interaction of a child with autism at five-years-and-ten-months of age, advances understanding of the psychological and epistemological underpinnings of human communication. ${ }^{2}$

Before introducing the study and analysis, we briefly discuss the notion of intersubjectivity. Central to both human sociability and successful communication, this notion also features prominently in all main approaches to autism, from psychology (e.g., Trevarthen and Aiken 2001) to phenomenology (e.g., Gallagher 2001), neuroscience (e.g., Gallese 2006), and anthropology (Ochs et al. 2004).

\section{Intersubjectivity and Autism}

Intersubjectivity can arguably be considered as both grounding communication and expressing communication's teleology. From Duranti's (2009) recent reflection on Husserl and the notion of intersubjectivity, we distinguish two different conceptualizations of intersubjectivity: one view, expressed by Schütz, considers intersubjectivity as "the fundamental ontological category of human existence" (Schütz 1966:82), and is close to Husserl's original ideas; the other perspective sees intersubjectivity as the communicative achievement of mutual understanding, a view first articulated by Garfinkel (1967) and later developed by conversation analysts (e.g., Sacks 1992; Schegloff 1992). In the former, intersubjectivity is conceived as first and foremost a condition for communication; in the latter, intersubjectivity as shared understanding is a product of communication (Duranti 2009).

We contend that both perspectives are to be engaged when examining interaction with individuals with autism. Recent studies in neuroscience have shown that primary access to understanding others that is rooted in embodied practices and not mediated by language is deficient in children with autism (Gallagher 2001, 2004). Gallagher, for instance, has observed that "some autistic children attempt to perform ... imitative action on the experimenter's body rather than on their own, and, thus, demonstrate a sensory-motor confusion between egocentric and allocentric spatial frameworks" (Gallagher 2001:104). ${ }^{3}$ If the nonconceptual basis for understanding others cannot be taken for granted in children with 
autism, then achieving with them the very specialized type of intersubjectivity that has come to be known as shared or mutual understanding, is all the more difficult and elaborated.

\section{Mutual Understanding in Everyday Communication}

In everyday communication, mutual understanding is rarely explicit and topicalized. Most frequently, mutual understanding is constructed, exhibited, and sustained by means of implicit procedures (Heritage 2007; Sacks 1992; Schegloff 1992). As Schegloff has highlighted, the management and accomplishment of intersubjectivity are woven into the procedural infrastructure of interaction (Schegloff 1992), so that "understandings are displayed en passant for the most part [...] as by-products of bits of talk designed in the first instance to do some action such as agreeing, answering, assessing, responding, requesting, and so on." (Schegloff 1992:1300). Epiphenomenally this results in the preference for sequence progressivity in interaction:

Moving from one element to a hearably-next-one with nothing intervening is the embodiment of, and the measure of, progressivity. Should something intervene between some element and what is hearable as a/the next one due-should something violate or interfere with their congruity, whether sound, next word, or next turn - it will be heard as qualifying the progressivity of the talk, and will be examined for its import, for what understanding should be accorded it. Each next element of such progression can be inspected to find how it reaffirms the understanding-so-far of what has preceded, or favors one or more of the several such understandings that are being entertained, or how it requires reconfiguration of that understanding. [Schegloff 2007:15]

The preference for sequence progressivity exemplifies a general conversational principle that Levinson (1987) has formulated as a "maxim of minimization." This maxim accounts for the fact that in conversational practices implicit methods of accomplishing conversational tasks are favored over explicit ones. ${ }^{4}$

These remarks can be linked with Wittgenstein's considerations of human interconnectedness and understanding. With a gesture that echoes Garfinkel's ethnomethodological program (Garfinkel 1967), Wittgenstein declines any attempt to articulate grand theories about intersubjectivity and the cognitive basis of "shared knowledge"; rather, he concerns himself with mundane and quotidian interpersonal affairs and exchanges. ${ }^{5}$ In Wittgenstein's perspective, the ways in which humans make and share meaning are not so much the product of intramental operations as they are of practical procedures interactionally and locally managed. Thus, mutual understanding is not conceived of as grasping what is in the other's mind but as being able to "go on" with each other (Shotter 1996). In Wittgenstein's words:

Try not to think of understanding as a "mental process" at all.-For that is the expression which confuses you. But ask yourself: in what sort of case, in what kind of circumstances, do we say, "Now I know how to go on." [1958:n. 154] 
The procedural infrastructure of interaction offers a host of resources that interlocutors routinely employ to display and evaluate understanding. In other words, talk in interaction is organized in such a way that from the way turns are tied to one another, interlocutors can implicitly and continuously assess their reciprocal alignment, and go on with next move if they detect no (or no significant) mismatch. Progressivity, namely the unfolding of the interaction, is thus ensured by its own functioning. This does not mean, however, that conversational moves are entirely predictable: there is a high degree of contingency in all interactions (Ford 2004; Schegloff 1996); possibilities that a turn will open are never entirely constrained, not even in the context of a question-answer exchange.

Intersubjectivity as rooted in communication is thus inherently and perpetually vulnerable. ${ }^{6}$ This intrinsic risk of breakdown in intersubjectivity cannot, however, be conceived of as a threat to successful communication, as an anomaly, as a foreign element lying outside the boundary of talk in interaction. The possibility of a lapse in mutual understanding is an attribute of sequence progressivity and an essential component of communication as encounter with the other. Sequence progressivity calls interlocutors to accept the risks of failure, thereby grounding communication not solely on epistemic bases but also on ethical premises. In other words, besides control over the hidden conversational mechanisms enabling the assumption of intersubjectivity, sequence progressivity also always implies mutual trust.

The study of communication with individuals with mental disabilities is particularly conducive to exploring the ethical dimension of encounters with the other, and of intersubjectivity as exceeding epistemological calculations. For instance, in verbal interaction with high functioning children with autism, adults recognize challenges to the security of intersubjective understanding. Consequently, in communication with these children, there often transpires a tension between the pursuit of intersubjectivity and sequence progressivity. $^{7}$

\section{Data and the Purpose of the Study}

In this article, we examine verbal interactions of a five-year-ten-month-old autistic boy, named Aaron, ${ }^{8}$ with his parents, tutors, and other family members as they engage in habitual and spontaneously occurring activities in the home. These activities include meals, personal hygiene, play, music lessons, and bedtime preparations.

The activities were video recorded biweekly for a month. They document four therapeutic sessions with a tutor, four meals (one with mother, one with grandmother, and two with both parents), two cleaning routines, four play sessions (with parents, tutor, and grandmother), and two sets of bedtime preparations. A total of about 16 hours of video recording were obtained. The video data were fully transcribed following conversation analytic conventions, adapted from Atkinson and Heritage (1984; see N. 9). 
As common in both the ethnographic tradition and microanalytic research on communication, we have chosen a single case study to maximize analytic depth and detail. A child's case study includes multiple sources of information, notably the child's history and present life, interviews with the parents and other significant interlocutors, and extended observation of the child's communicative and noncommunicative behavior. Rather than making findings idiosyncratic, this methodological approach familiarizes the researchers with the lifeworld of the child and the variety of his or her interactive resources and habits. In this way it allows robust analyses based on a thorough comprehension of the challenges a child meets and the solution he or she finds.

Our approach to the analysis of the data extracts presented in this article is primarily informed by work in conversation analysis (Sacks et al. 1974; Wootton 1997) and developmental pragmatics (Ochs and Schieffelin 1979; Snow 1986). This approach examines communicative behavior within its local sequential context of production and the details of the design and intonational features of each utterance.

Aaron was diagnosed with autism at age three, although his parents began wondering about his behavior when he was 10-12 months old. At that time they noticed that Aaron's motor activities were not progressing (notably, he had not started crawling), and he often looked disoriented or lost. When he was 18 months old, Aaron was given a "possible" diagnosis of Pervasive Developmental Disorder-Not Otherwise Specified (PDD-NOS). Although initially (beginning at 13 months) Aaron underwent physical and speech therapy, after being diagnosed with PDD-NOS he began receiving different forms of more specific interventions: Floortime from 22 months; Applied Behavioral Analysis (ABA) therapy from 2.5 years; and Pivotal Response Training (PRT) shortly after being officially diagnosed with autism. At the time of data collection Aaron was receiving one-on-one tutoring (mainly Floortime) ten hours per week while also attending his last year of regular kindergarten.

Although no intelligence test was administered to Aaron when he was diagnosed with autism or later on, our observation did not find evidence of significant cognitive delay: he was capable to read, write, and do arithmetic at a level comparable if not higher than that of normally developing children of his age. His parents report that Aaron's verbal communication was developmentally delayed. He was only babbling until well beyond 18 months. His later language development was characterized by echolalia and formulaic repetitions. Aaron's linguistic repertoire at the time of data collection is the object of detailed analysis in what follows.

We first consider Aaron's repertoire of communicative moves - that is, the range of strategies that this autistic boy deploys in interacting verbally with his interlocutors. As we illustrate, this set of communicative resources is limited and characterized by dependence on interlocutors' utterances. Although lacking a host of conversational resources exhibited by normally developing children of his age - notably, protests, assessments, accounts, narrations-Aaron strategically uses the limited set of communicative moves at his disposal to propel sequence progressivity. Insofar as Aaron's contributions to conversation (1) are responses to his interlocutors' initiations or continuations of his interlocutors' prior talk, 
and (2) in turn trigger further contributions from his conversational partners, we consider them to be "progressivity techniques."

We then consider how Aaron's family members and tutor respond to his conversational moves and the conversational keys that are most conducive to his engagement and contribution to the exchange to understand the joint accomplishments involved in interactions with Aaron.

\section{Aaron's Repertoire of Progressivity Techniques}

Aaron's repertoire of progressivity techniques includes moves typically produced in the sequentially second position and others more frequently offered in the fourth or subsequent positions. We begin by considering moves that most frequently occur in second position, namely after another speaker has issued some kind of initiating move-a question, a directive, an assessment. Aaron's response will likely be an appendor or tag question. Then we examine the devices that are sequentially positioned in subsequent turns: reformulations and expansions; norm formulations; and abstractions or generalizations. We illustrate how the progressivity moves mobilized in subsequent positions draw from and build on conversational material triggered by second-position techniques.

\section{Appendor and Tag Questions}

The sequence continuations Aaron uses most often are appendor questions (Sacks 1992), namely prepositional phrases and adverbial clauses syntactically affixed to the immediately preceding sentence. Consider one illustration of this move in Example 1 below. The Paxter family is at the dinner table. Dinner has just started. Aaron and Dad have begun eating while Mom is still moving around in the kitchen, bringing things to the table. ${ }^{9}$

Example 1-Tape \#3 Dinner with Mom and Dad

\begin{tabular}{|c|c|c|}
\hline 1 & MOM & Aaron, could you put that napkin in your la:p? \\
\hline 2 & & $\begin{array}{l}\text { ((Aaron looks around and touches the paper napkin on the dish side without } \\
\text { picking it up)) }\end{array}$ \\
\hline 3 & $\mathrm{DAD}$ & Watch Dad ((bolds up folded napkin in front of Aaron)) ( ) \\
\hline 4 & & Aaron? Napkin, ((moves napkin closer to bis chest and straightens it between hands)) \\
\hline 5 & & Lap. ((lowers hands with napkin under the table)) \\
\hline 6 & & ((Aaron picks up the napkin and brings it under the table, presumably to bis lap)) \\
\hline 7 & $\mathrm{DAD}$ & Thank [you. \\
\hline 8 & MOM & [There you go:. \\
\hline 9 & & ((Aaron looks toward the door behind him and puts the napkin back on the table)) \\
\hline 10 & $\mathrm{DAD}$ & No. Put it ba::ck. \\
\hline 11 & & ((Aaron lowers his hand with the napkin again $))$ \\
\hline
\end{tabular}




$\begin{array}{llll}12 & \text { DAD } & & \text { Thank you:. } \\ 13 & \text { AARON } \rightarrow & \text { Because } \uparrow \text { it's? ((standing } u p)) \\ 14 & \text { DAD } & & \text { A napkin. }= \\ 15 & & =\text { You finished it. I know you're almost done. } \\ 16 & & & \text { Please sit. } \\ 17 & & ((\text { Aaron sits down })) \\ 18 & \text { AARON } \rightarrow & \text { Because it's } \uparrow \underline{\text { dinnertime. }} . \\ 19 & \text { DAD } & & \text { It is dinnertime }\end{array}$

Aaron first complies with both his parents' instructions to place the napkin on his lap, but then, seemingly about to stand up and leave the room, puts it back on the table. His move gets noticed by his father, who immediately issues a corrective directive (ln. 10). Aaron complies and the father acknowledges (ln. 12). At this point Aaron formulates an appendor question ("Because $\uparrow$ it's?" ln. 13) that extends the father's imperative and prompts the father to complete it. His father responds to Aaron's elicitation (ln. 14) and then immediately switches to the plane of behavioral control (ln. 16). After sitting down again, thus pragmatically complying with his father's directive, Aaron utters the correct answer to his own question (ln. 18), showing that the intended goal of his appendor was the formulation of the household rule underlying the directives just issued.

Aaron's move is interesting in many ways: first, it continues after and expands on a behavioral directive (ln. 1), which in itself would not require a verbal reply. Second, it is syntactically shaped not only as dependent on the father's utterance but also as progressing from it, with the casual conjunction followed by pronoun and auxiliary contraction with marked interrogative intonation ("Because $\uparrow$ it’s?" In. 13). In this way Aaron casts his father's demand as part of common family lore, something that "we all [should] know." Indeed, appeals to rules and norms are very frequently employed by Aaron's parents in their attempts to control and rectify his behavior.

Thus, in this exchange Aaron's appendor question has incited progression from within his interlocutor's own discourse, and by means of commonly held information. At the same time, Aaron's appeal to the norm - first through an appended prompt and then an explicit formulation - changes the relational balance by countering the father's authority: behavioral compliance is displaced by an abstract standard, with which Aaron displays familiarity. Moreover, the interrogative move allows Aaron to gain some control over his controller. Appendor questions have in fact been considered indicative of asymmetry in adult-adult interaction (e.g., Itakura 2001; Sacks 1992) in that the speaker controls the interlocutor by constraining the content of his or her communicative action.

The appended utterance we consider next is "Or else?," the most prevalent progressivity move and appendor question in Aaron's repertoire. Its pervasiveness in the child's communication was once acknowledged by the father, who summoned his son by calling him 
"Aaron or else Paxter"! Two brief illustrations (Examples 2a and 3) are offered one after the other; then this progressivity move is discussed in detail.

The first extract below (Example 2a) contains the "or else" appendor question as well as a tag question. A tag question is a grammatical structure-for example, "isn't it?" - attached at the end of an otherwise noninterrogative utterance that creates a slot for the interlocutor to take the subsequent turn (Sacks et al. 1974). As such, tag questions constitute another kind of progressivity move. Aaron often affixes this type of question, notably "right?," to his interlocutor's declarative statements. In Example 2a, excerpted from an approximately 30-minute play episode, Aaron is playing Perfection with his after-school tutor, Shelly (an additional segment of this play episode, Example 2b, is considered later). The game requires players to insert differently shaped plastic pieces into corresponding slots on a five-by-five platform. The task is time restricted as marked by an audible timer. As the time passes the platform rises, and when all of the time has elapsed it pops up, making a loud noise and ejecting all of the inserted pieces.

Example 2a-Tape \#7 Perfection Game

$\begin{array}{llll}1 & \text { SHELLY } & & \text { Okay. Okay go ((pushes down platform; timer starts clicking)) } \\ 2 & \text { AARON } & & \text { Look o:ut. } \\ 3 & \text { SHELLY } & & \text { All ri:ght. Let's see if we can go= } \\ 4 & \text { AARON } & =\text { Pretty fa:st } \\ 5 & \text { SHELLY } & & \text { If we can go fast } \\ 6 & \text { AARON } & \rightarrow & \text { Or e ::lse } \\ 7 & \text { SHELLY } & & \text { Or else it will pop up on us } \\ 8 & \text { AARON } & \rightarrow & \text { Really? (.) Right, (laughing)) } \\ 9 & \text { SHELLY } & & \text { Ri ::ght. } \\ 10 & \text { AARON } & \rightarrow & \text { Or else ((smiling) }) \\ 11 & \text { SHELLY } & & \text { It will go pop [and it will be really scary } \\ 12 & \text { AARON } & & \end{array}$

Example 3 is excerpted from a family meal, with Mom, Dad, and Aaron seated at the kitchen table:

Example 3-Tape \#3 Dinner with Mom and Dad

$\begin{array}{lll}1 & \text { DAD } & \text { Aaron, use the fork. Aaron. (.) Fork } \\ 2 & & (8.0) \text { ((Aaron picks up the fork by making a fist around the bandle and continues eating)) } \\ 3 & \text { DAD } & \begin{array}{l}\text { That's good. (.) How 'bout holding it this way? } \\ ((\text { demonstrates proper way to bold a fork outside camera's view)) }\end{array} \\ 4 & \text { AARON } \rightarrow \quad & \text { Or else? }\end{array}$


5 DAD ((while laughing softly)) Or e:lse? (.)

6

You look like a caveman. You don't wanna do it caveman style.

In contrast to Aaron's earlier noted use of "because?," the question "or else?" introduces a counterfactual description. In Examples $2 \mathrm{a}$ and 3, the counterfactuals are the undesirable consequences of noncompliance (i.e., game pieces being ejected or looking like a caveman). In other instances, they represent punishment for disobedience or a jocular threat like "tickle torture" (see Examples 7b-c below).

The "or else" question's peculiarity is that it shifts discourse to a hypothetical plane, thus, a "theoretical" one in which the need for a next move-for example, after a directive-is suspended. Aaron orients "or else" toward normative knowledge, be it generally valid or locally set in place by the family. This is similar to his use of "because." Insofar as they are produced where behavioral compliance is expected, Aaron's progressivity moves are incisive, recontextualizing actions: under the strictures of a normative sequence, neither full compliance nor unambiguous rejection is produced. Aaron wedges himself into a liminal position, suspending the behavioral demands and launching a new language game.

Aaron's “or else” maneuver reminded us of Bartleby's notorious formula, "I would prefer not to" (in Melville's novel Bartleby the Scrivener). As Deleuze (1997) has argued, by neither accepting nor refusing his employer's assignments Bartleby short-circuits the modus operandi of power as imposing choices. The clerk's decision to refrain from choosing is both disarming and crippling in that it opens up an elusive, indeterminate space in which language itself in its conventionality is put in danger, brought within sight of its limits. Aaron's “or else," like Bartleby's formula, freezes the conventionally expected response to the instruction and launches a different language game that engages a different participatory logic. When produced after a directive, Aaron's “or else” question constitutes a threat to the immediate reestablishment of the behavioral, moral, and social order. Aware of the risks introduced by this move, when facing matters of serious concern to them, the parents may block Aaron's rejoinder, as in the following extract:

Example 4-Tape \#3 Dinner with Mom and Dad

$2 \mathrm{MOM}$

3 AARON

$4 \quad \mathrm{DAD}$

5

$6 \mathrm{MOM} \rightarrow(($ taps Aaron's back $))$ Can you come around?

7 AARON $\rightarrow \quad(($ turns head slightly to face Mom; smiling))

((reaches over and pats Aaron's back)) Are you tired?

No thanks

No thanks ((mimicking Aaron and laughing slightly))

(3.0) ((Mom bolds band on Aaron's back))

(4.0) ((Aaron has bis back to Mom and Dad and gazes in the direction of the dishwasher))

$\rightarrow \quad$ Or else? 


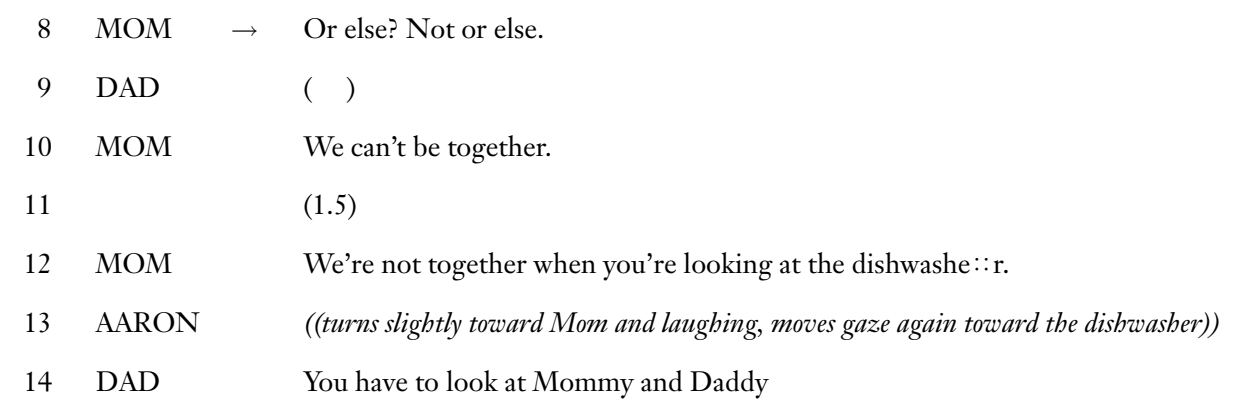

Aaron's looking away from the parents while sitting at the dinner table prompts his mother's inquiry about being tired (ln. 2). After his negative answer, his mother asks him directly to turn around (ln. 6). The question, hearable as a directive, leads to Aaron's most frequent appendor, with a smile that seems to be hinting at the familiar game. The mother, by refusing to answer ("Or else? Not or else.," In. 8), walls off the interactional sequence that "or else" typically gives way to (analyzed further in the next section): while taking up Aaron's question would secure his reengagement in their interaction, it would also imply backing away from the seriousness of the directive frame. The father says something seemingly related to the question (although unintelligible to us, ln. 9) so the mother ends up responding to Aaron's “or else?” (ln. 10 and 12) nevertheless.

It can thus be argued that Aaron's progressivity moves, while limited in kind and scope, enable him to gain some control over the exchange and to display some degree of subjective positionality and competence in communicating with his interlocutors. For the parents to secure control of the exchange and to pursue their immediate goals, it is often necessary not to respond to Aaron's rejoinders.

\section{Expansions of Answers to Appendors}

Examples 1-4 show how Aaron manages to propel the unfolding of conversational sequences in repeated, minimal increments. Appendor and tag questions are effective means of returning the conversational floor to the prior speaker and prompting him or her to produce further talk (Sacks 1992). In this section we discuss how in this way Aaron acquires additional conversational material, which he then capitalizes on in his subsequent contributions.

Repetitions and reformulations. Aaron's most frequent question does not project just one further move, but is in fact a trigger for a more substantive interactional language activity. By the time the conversational sequence reaches the fourth or following positions Aaron has often produced a more substantial contribution, by partially repeating or reformulating his interlocutor's prior utterances. We can appreciate this by returning to Example 2a and examining how it unfolds further:

Example 2b-Tape \#7 Perfection Game

1 SHELLY Okay. Okay go ((pushes down platform; timer starts clicking))

2 AARON Look o:ut. 


\begin{tabular}{|c|c|c|c|}
\hline 3 & SHELLY & & All ri:ght. Let's see if we can go= \\
\hline 4 & AARON & & $=$ Pretty fa:st \\
\hline 5 & SHELLY & & If we can go fast \\
\hline 6 & AARON & $\rightarrow$ & Or e::lse \\
\hline 7 & SHELLY & $\rightarrow$ & Or else it will pop up on us \\
\hline 8 & AARON & & Really? (.) Right, ((laughing)) \\
\hline 9 & SHELLY & & Ri::ght. \\
\hline 10 & AARON & & Or else ((smiling)) \\
\hline 11 & SHELLY & & It will go pop [and it will be really scary \\
\hline 12 & AARON & & {$[(($ giggles $))$} \\
\hline 13 & SHELLY & & Oh. ((pretend screaming; bigh pitch)) A:: :h A:: :h \\
\hline 14 & AARON & $\rightarrow$ & I don't want it- (.) I DON'T WANT IT TO POP \\
\hline 15 & SHELLY & & NO I don't ei:ther \\
\hline 16 & AARON & $\rightarrow$ & I don't want it to pop \\
\hline
\end{tabular}

Aaron's appendor and tag questions (ln. 6, 8, and 10) prompt Shelly to formulate the potentially impending negative outcome of the game in progress (ln. 7 and 11). Then, partially rephrasing Shelly's utterance, Aaron produces an assertion in the first person (ln. 14), expressing a stance vis-à-vis the physical and psychological consequences envisaged by Shelly if they do not play the game fast enough. Such a subjectivity display, with the first person pronoun and the volitional verb, is rarely encountered in Aaron's communication and almost never found in sequence initial position. Aaron's techniques are revealed by these examples as achieving not only interactional engagement but also psychological expression by having the interlocutor establish the psychological key and temperature of the interaction itself. Aaron's repetition of the question is devised to obtain a reply that would justify his emphatic uptake and expression of a negative stance; here, Shelly's first answer, limited to the mechanics of the game, was not enough, while the psychological reaction added in her second answer ("it will be really scary," ln. 11) is apt to generate Aaron's subsequent repeated and gradually more emphatic negative reformulation (“I don't want it- (.) I DON’T WANT IT TO POP,” ln. 14).

This sequence shows that Aaron's appendors are not just issued in a rote way after any behavioral prompt; nor are his continuations standardized independently of the answers they yield. On the contrary, the ideal responses to "or else" are imbued with enough psychological content (be it humorous, or explicitly emotional, or both, as in this case) to extend their value onto Aaron's reformulation of them.

The following example provides a further illustration. This time the progressity moves are not focused on a common objective (e.g., not wanting the machine to pop up); rather, they express a somewhat funny positive stance toward a negative statement of fact that Aaron's mother sketches out in response to "or else." Mom is trying to persuade Aaron to take a bath: 
Example 5-Tape \#2 Bath time

\begin{tabular}{|c|c|c|c|}
\hline 1 & MOM & & Aaron! (.) You've got to take a ba:th. \\
\hline 2 & AARON & $\rightarrow$ & Because? ((biccup)) \\
\hline 3 & MOM & & Cause you $[\mathrm{s}-$ \\
\hline 4 & AARON & $\rightarrow$ & [Or or else? \\
\hline 5 & MOM & & Or else you're gonna stink. \\
\hline 6 & AARON & & $(($ laughs $))$ \\
\hline 7 & MOM & $\rightarrow$ & You won't have any friends 'cause you'll stink too bad. \\
\hline 8 & AARON & & $(($ laughs $))$ \\
\hline 9 & MOM & & Is that funny? \\
\hline 10 & AARON & $\rightarrow$ & Yeah, I want to stink too bad! ((laughter)) \\
\hline 11 & MOM & & You wanna stink too bad? \\
\hline 12 & AARON & & Yes! \\
\hline 13 & MOM & & You don't want to have any friends? \\
\hline 14 & & & (1.0) ((guiding Aaron to the bathroom)) \\
\hline 15 & MOM & & Let's take a look. \\
\hline 16 & & & (2.0) ((opening the door and going inside)) \\
\hline 17 & MOM & & O:kay. \\
\hline 18 & AARON & & (Will/We'll) not take a ba:th. \\
\hline 19 & MOM & & (Now we go to the bathroom) ((entering the bathroom)) \\
\hline 20 & AARON & $\rightarrow$ & Or else? \\
\hline 21 & MOM & $\rightarrow$ & Or else. $=$ \\
\hline 22 & AARON & $\rightarrow$ & $\begin{array}{l}\text { = Stink. ((closing the bathroom door, seeing camera person, } \\
\text { and staring straight into the camera)) }\end{array}$ \\
\hline 23 & MOM & $\rightarrow$ & $\begin{array}{l}\text { Or else stink. Okay. Now ( ) here Aaron ((preparing the bathroom for } \\
\text { the bath but partially obscured by the door)) }\end{array}$ \\
\hline
\end{tabular}

After Mom's directive in line 1, Aaron asks "because," but self-repairs with "or else" right after the mother has started answering. She then catches on with the second question format and states the negative consequence of not taking a bath, namely that he will "stink too bad" and “won't have any friends" (ln. 5 and 7). This time favoring her son's uses of appendors as sequential prompts, the mother continues with imaginary scenarios and comments, to which Aaron replies by laughing, but produces at last one utterance reformulating his mother's (ln. 10). As in Example 2b, here as well Aaron draws from his interlocutor's immediate utterances to produce his next contribution as an ego-assertive formulation ("I want to stink too bad!") The humorous potential suggested by his mother's exaggerated 
descriptions seems to create a particularly favorable context for Aaron's expressions of subjective positionality.

Examples 2b and 5 show that "or else," if responded to, generates a slot (B2) for a further move:

A1: directive or exhortative ("do x," "let's do x")

B1: "or else" appendor question

A2: consequences (“y will happen”)

B2: expression of stance in relation to consequences ("I want y"/"I don't want y")

A3:...

Moreover, the expression of stance in B2, often running counter normative expectations, invites reaction and elaboration. In Example 5, repair initiations as expressions of surprise ("You wanna stink too bad?" "You don't want to have any friends?" ln. 11 and 13), follow Aaron's statement "I want to stink too bad" and in turn elicit further reply from the child ("Yes," ln. 12).

The last two examples display alternative trajectories in the alignment of Aaron's sequential third parts. In Example 2b, after the tutor's collective exhortative "Let's see if we can go $=[\ldots]$ If we can go fast" and the expression of consequences affecting both participants "Or else it will pop up on us" Aaron aligns against the consequence that his interlocutor has framed as undesirable for both ("I DON"T WANT IT TO POP”). In Example 5, where the suggested conduct impinges on the child only, Aaron aligns in favor of the potential events that his interlocutor has portrayed as undesirable ("I want to stink too bad").

We propose that the expressions of desire for negative events contain ironic innuendos. Aaron's mother often goes along with Aaron and paints her counterfactual descriptions with markedly emphatic brushes, evoking disastrous or ridiculous scenarios.

Norm formulations and abstractions or generalizations. Aaron's displays of competence often consist of norm formulations, abstractions, and generalizations. We saw an instance of such a display in Example 1: "because it's dinnertime" (ln. 18). We have argued that the rule formulation was a strong move, by which the boy countered his father's authority. We will now explore in more detail the function of this type of third position turn. Example 6 unfolds after a further occurrence of the now familiar "or else" progressivity sequence, in which Aaron claimed to want to be hot while negotiating with Mom the temperature of water for his bath. Shortly thereafter, Mom and Aaron are still busy with water regulation, and the following sequence comes about:

Example 6-Tape \#2 Bath time

1 MOM Okay, now put the plug in. Yep. There we go.

2 AARON ((quiet singing and bumming)) 


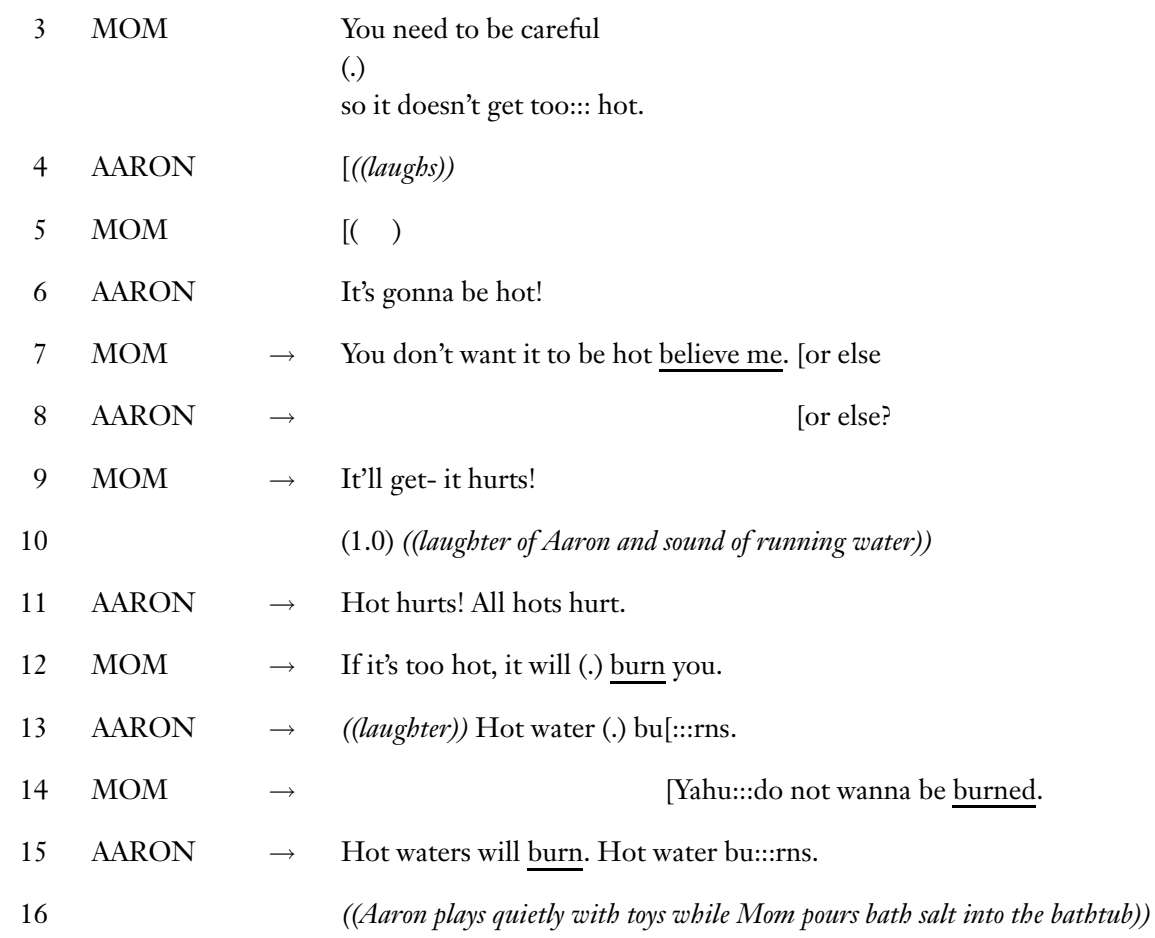

With a discursive move that strikingly resembles Aaron's most typical ones, Mom herself deploys the "or else" as a follow-up to her warning (ln. 7). Aaron, in fact, utters his question simultaneously (ln. 8). Then Mom cautions her son about getting hurt as the possible consequence of letting the hot water run. Drawing on Mom's prior turn, Aaron formulates a double generalization ("hot hurts" and "all hots hurt," ln. 11). The mother again picks up an element from Aaron's talk (i.e., "hot") and offers an expansion, rather general itself (ln. 12). And Aaron then builds another generalization based on it ("hot water burns," ln. 13), which brings the sequence to its close. ${ }^{10}$ In other words, while heavily drawing from conversational material produced by his interlocutor previously in the sequence or from frequently evoked shared knowledge, Aaron is able to use norm formulations, abstractions, and generalizations as progressivity resources to exercise considerable conversational control and bring the sequence to its close, having the last word on the matter.

Aaron's initiating and shifting actions are particularly significant considering that the boy often deploys them in sequences set off by adult-issued behavioral directives. Pragmatically speaking, as already mentioned above, behavioral directives are not prototypical conversation triggers: they are primarily aimed at correcting untoward conduct. However, they also bear an indexical value in that they point to a normative horizon, justifying their deployment at any given moment. According to the family's ethics, when a behavioral directive is issued, a general underlying rule is always retrievable and can be spelled out: a napkin goes on one's lap "because it's dinnertime;" in the bathtub cold water is turned on first because "hot water burns." Alternatively, some negative consequences of a specific behavior can be evoked: a bath is due, "or else stink;" Perfection must be played fast, "or else it pops." Thus, directives' indexical character makes them propitious anchors for progressivity moves. 
Manifestly, Aaron is addressed with numerous such speech acts: adding to the already high frequency generally characteristic of child-directed communication is the fact that Aaron has a syndrome that is seen as engendering untoward or perilous conduct (e.g., avoiding gaze with interlocutors). Furthermore, children with autism are reported to display a better grasp of directives over other speech act types in both comprehension and production after the preverbal stage (Baron-Cohen 1989a, 1989b; Loveland et al. 1988; Ochs et al. 2004). These factors are likely to result in a cumulative bias toward directive style in parents' talk. Aaron's progressivity techniques can thus be seen as adept although limited maneuvers by which the child manages to deflect the pragmatic constraints of directive talk and exploit normative references in a way that is more empowering than limiting. At the same time, it is important to consider that norm formulations, abstractions, and generalizations evoke shared normative and epistemic horizons. As such, they can constitute building blocks of intersubjectivity, evoking and reinstantiating mutual understanding.

\section{Precarious Exchanges: The Intrinsic Risk of Communication and the Bet on Trust}

In the first section of this article, we discussed how sequence progressivity inherently bears the risk of breakdown in intersubjectivity. We also suggested that going on with the other in conversation implies mutual trust. The possibility of communication breakdown, the risk of failure, uncertainty, and indeterminacy are essential to communication as encounter with the other.

These suggestions find support and inspiration in some of the claims articulated by Derrida in the essay "Signature Event Context." In particular, in his critical examination of Austin's speech act theory Derrida emphasizes that Austin's notion of "infelicity" points to the fact that all conventional acts are vulnerable to failure. However, Derrida argues, Austin confines infelicities to the exterior of communication - that is, to its contextual surroundings. The risk of failure, thus, is not conceived of as "an essential predicate or law:"

Austin does not ask himself what consequences derive from the fact that something possible - a possible risk - is always possible, is somehow a necessary possibility. And if, such a necessary possibility of failure being granted, it still constitutes an accident. What is a success when the possibility of failure continues to constitute its structure? [Derrida $1982: 324]$

Instead, Derrida poses the following question:

[I]s this general possibility necessarily that of a failure or a trap into which language might fall, or in which language might lose itself, as if in an abyss situated outside or in front of it? [...] In other words, does the generality of the risk admitted by Austin surround language like a kind of a ditch, a place of external perdition into which locution might never venture, that it might avoid by remaining at home, in itself, sheltered by its essence or telos? Or indeed is this risk, on the contrary, its internal and positive condition of possibility? this outside its inside? the very force and law of its emergence? [Derrida 1982:325] 
We are thus prompted to ask: what happens when Aaron's interlocutors accept the risk to go on with the boy's most hazardous progressivity moves (e.g., the "or else" appendor question after a directive aiming at stopping a typical autistic behavior)? What happens when the interlocutor ratifies Aaron's reframing and enters the liminal conversational space opened by the child? There are only a few instances of these precarious exchanges. In what follows we analyze, in its rather prolonged unfolding, one of these exchanges, in which Aaron and his mother are engaged. We show that sequence progressivity in the first part of the exchange is constructed by maneuvering on the formal plane, primarily through format-tying moves (Sacks 1992). Alliterations, repetitions, and variations constitute the matrix of sustained attunement between Aaron and his mother. In this context the mother inserts a narrative innuendo that the child is able to respond to with a display of remarkable communicative competence and attunement: Aaron introduces another narrative and invites his mother to engage in joint remembering and telling.

The sequence begins after Aaron and his mother have been playing a duet at the piano. Although Mom is still playing a few notes, Aaron leaves the living room and heads toward the parents' bedroom. From there he calls Mom, who was already on her way to join him. As she enters the room, Mom finds Aaron jumping on the bed and reacts with mock surprise and indignation. She overtly pretends to be outraged and pursues control of Aaron's body by holding his arms and resting her torso on his legs. She then begins "tickle torturing" him. ${ }^{11}$ Aaron is amused, but after a few seconds he escapes his mother's grip and goes to sit at the edge of the bed, with his back to her. Aaron's bodily position indicates withdrawal, but the mother does not issue a directive to have him turn and reengage (Example 7a): a bug enters the bedroom through the window and she directs her son's attention to it. In other words, rather than demanding faceto-face involvement at a moment when Aaron seems to require distance, the mother invites him to pay shared attention to a third object. In addition, she maintains a playful attitude by using a highly modulated sing-song tone as if she were following with her voice the bug's waving lines. Aaron reengages in their interaction:

Example 7a-Tape \#2 Aaron and Mom on the bed
((a bug enters the room. Mom notices it))
$40 \mathrm{MOM}$
o-ho bug. (.) bug.
41 AARON
Where's the bu:g.
42 MOM
I see it. Right there ((claps hands to get the bug)) ah. Watch him.
(0.8) here he comes. (.) he's $\uparrow$ comi:ng, ((sing-song voice))
43 AARON
Upstairs? ((looking upward toward the window))
44 MOM
He's going up the window:: ((with same prosodic contour as last line in turn 42))
45 AARON
Where's the bug.
$46 \mathrm{MOM}$
Don't let him bite you. I don't [know:.
47 AARON
$[($ (laughs $))$
$48 \mathrm{MOM}$
He's comin- he's gonna come for you in a little bit 
From lines 40 to 47 the turns are brief. They present several repetitions, alliterations (bug, bite, bit; comes, coming, comin-, come; there, here, where) and prosodic parallelisms across both turns and participants. Such a form of communication allows a tight interconnection between participants, whose turns not only are rapidly alternating but also are assembled pretty much with the same word sounds. Furthermore, these moves are indexical of a symmetric positioning of the two interactants.

At this point Aaron leaves the bed to be able to jump on it again. His mother's mock frustration (ln. 50) at the fact that Aaron has stepped on the dog's blanket, and subsequent mock warning not to repeat the undesired action (ln. 54) invite engagement in another playful exchange:

Example 7b-Tape \#2 Aaron and Mom on the bed

\begin{tabular}{|c|c|c|}
\hline 50 & MOM & o-ho Aaron. You just sat on the Yachi bed \\
\hline 51 & AARON & Hhe. [hehehehe ((laugbs)) \\
\hline 52 & MOM & [( ) the Yachi [blanket \\
\hline 53 & AARON & [Hehe a:rh:: ((stepping on the dog blanket)) \\
\hline 54 & MOM & DON’T GET ON THE YACHI BLANKET. \\
\hline 55 & AARON & [hehe he hu hehe huhe heeh ((laugbs)) \\
\hline 56 & MOM & [OH MY GO:SH. LOOK what you did ((mock terrified voice)) \\
\hline 57 & AARON & Hehe [heh hehe hehuhe ((laugbs)) \\
\hline 58 & MOM & [YOU GOT ON THE BAD BED ((tickling Aaron)) \\
\hline 59 & AARON & Hehe hiih ((rolling on bed)) \\
\hline 60 & MOM & You're gonna get bug bites. From Yachi. \\
\hline 61 & AARON & He $\uparrow$ huhu ((laugbs)) (.) or else? \\
\hline 62 & MOM & $\begin{array}{l}\text { Or e:lse you're gonna be covered in bug bites } \\
((\text { tickling Aaron's bare legs }))\end{array}$ \\
\hline 63 & AARON & $\begin{array}{l}\text { Hehe hehu hehu ((laughs)) no seat on the } \\
\text { [bug bed, ((laugbing)) }\end{array}$ \\
\hline 64 & MOM & [Yach- yachi's bug blanket. \\
\hline 65 & AARON & I'll sit on Yachi's bug bed or else? \\
\hline 66 & MOM & You're gonna get covered with bug bites. ((tickling Aaron on legs)) \\
\hline 67 & AARON & $\begin{array}{l}\text { Ha ha ha ha hu ha ((laughs with mouth on pillow)) you'll be } \\
\text { covered in bug bites. }\end{array}$ \\
\hline 68 & MOM & Yeah. \\
\hline
\end{tabular}

Segment $7 \mathrm{~b}$ above is centered around one piece of home regulation, namely not to touch the dog blanket lying on the bed because it may host insects. However, Mom's turns are all keyed in the playful, mock reproaching tone and both her noticings of Aaron's violation (ln. 50, 56, and 58), and her corrective directive (ln. 54) are pronounced with the emphatic and prolonged sounds of 
overenacted surprise and fear. Aaron laughs throughout, and continues when mother starts tickling him. With the tickling, that starts in line 58, she introduces the consequences of Aaron's behavior (verbally made explicit in $\ln .60$ "You're gonna get bug bites. From Yachi"), anticipating and actually triggering his son's "or else" questions (ln. 61). She promptly replies to that with an extended version of her former turn ("You're gonna get covered with bug bites") and more tickling on Aaron's legs. Aaron goes on with a rule formulation ("no seat on the bug bed") that Mom overlaps completing his sentence with again a more detailed and exact version (Aaron's "bug bed" becomes "Yachi's bug blanket"). The "or else" sequence is then repeated (ln. 65-68) with Aaron offering the "or else" trigger and Mom reiterating the consequences of the rule violation.

In summary, Mom and Aaron have been producing together, with a high rate of mutual repetition and reformulation, a parodied and playful version of the typical sequence (directive- or else-consequence-rule formulation) that we described earlier on. Mom has started it picking up a violation to home rules, thus exploiting Aaron's typical progressivity moves to engage her son in dialogue and amuse him. In this way, Aaron's stereotypical verbal contributions are not simply accepted but in fact valued as functional to continuation of the play. Mom has been also enacting physically the undesirable consequences of the rule violation, creating an episode of intense closeness and positive affect. All the same, she has been offering her son well-formulated linguistic expressions that Aaron picks up and recycles in his subsequent turns.

As the episode unfolds Aaron displays significantly more initiative than earlier-for instance, pertinently shifting the topic in a stepwise manner (Sacks 1992), primarily relying on repetition and word sounds:

Example 7c-Tape \#2 Aaron and Mom on the bed

\begin{tabular}{|c|c|c|c|}
\hline 123 & MOM & & $\begin{array}{l}\text { You know what ((looking at watch)) } \\
[\uparrow \text { hu:: h. wouhi::. } \uparrow \text { Hi:: :youh. ((tickling Aaron }))\end{array}$ \\
\hline 124 & AARON & & {$[(($ laughs and moves on the bed $))$} \\
\hline 125 & MOM & & †you sti:nk ((sing song voice)) \\
\hline 126 & AARON & $\rightarrow$ & $(($ laugbs $))$ I want [spiders, \\
\hline 127 & MOM & & [stink \\
\hline 128 & AARON & $\rightarrow$ & To bite. \\
\hline 129 & MOM & & Yo- how come? \\
\hline 130 & AARON & & ((laugbs and squishes face on the pillow)) \\
\hline 131 & MOM & & You wanna get hurt? \\
\hline 132 & AARON & & No:: \\
\hline 133 & MOM & & Why do you want spiders to bite? \\
\hline 134 & & & $(2.5)$ \\
\hline 135 & AARON & & Ah (.) I want spiders (.) biting \\
\hline 136 & MOM & & $\begin{array}{l}\text { Where? (1.0) right here? ((moving band toward } \\
\text { Aaron's back as to resume the tickling)) }\end{array}$ \\
\hline
\end{tabular}




\begin{tabular}{|c|c|c|c|}
\hline 137 & AARON & $\rightarrow$ & ((recoils and removes Mom's hand)) \\
\hline & & $\rightarrow$ & How about (.) bees? ((laughing)) \\
\hline 138 & MOM & & Bees? \\
\hline 139 & AARON & $\rightarrow$ & A bee (sto-) (.) sti:ng ((laughing)) \\
\hline 140 & MOM & & M:h you want it to sting? ((smiling tone)) How come? \\
\hline 141 & AARON & & {$[(($ laughs $))$} \\
\hline 142 & MOM & & [Do you wanna get hurt? \\
\hline 143 & AARON & & $\begin{array}{l}\text { No:: (laughing)) (you) don't wanna get hurt. } \\
\text { ((reported speech tone of a warning)) }\end{array}$ \\
\hline
\end{tabular}

In Example 7c, Aaron first introduces another animal, the spider that bites as the bug does (ln. 126 and 128). Then he mentions the bee (ln. 137 and 139), which stings, an action closely related to bug and spider biting. It is also worth noting that "sting" is formally and acoustically close to "stink," a word introduced by the mother just a few seconds earlier (ln. 125 and 127). Mom takes up both of Aaron's proposals with a trio of questions ("How come?"; "Do you want spider/bee to bite/sting?"; "Do you wanna get hurt?"), uttered in a tone of mock surprise. These questions trigger the child to produce amused denials of what he has just previously stated. It is evident that both Mom and Aaron have moved the conversation forward and are enjoying its unfolding by poetically playing with its formal aspects and challenging its semantic coherence. The sequence culminates then in pure speech and sound play, a vocal, rhythmical duet of consonant variation around the "bug" sounds, starting with Aaron's "bug hug" in line 229:

Example 7d-Tape \#2 Aaron and Mom on the bed

$\begin{array}{lllc}226 & \text { MOM } & & \text { That's the bug blanket } \\ 227 & \text { AARON } & \rightarrow & (\text { (laughs, turns to reach bed side) }) \text { bug } \\ 228 & \text { MOM } & \rightarrow & \text { It's [the bug blanket } \\ 229 & \text { AARON } & \rightarrow & {[\text { bug- }(.) \text { bug hug }((\text { getting on bed }))} \\ 230 & \text { MOM } & \rightarrow & \text { Bug hug } \\ 231 & \text { AARON } & & (\text { (laughs) }) \\ 232 & \text { MOM } & \rightarrow & \text { Bug hug }(.) \text { bat bath } \\ 233 & \text { AARON } & \rightarrow & \text { Wo no bath } \\ 234 & \text { MOM } & \rightarrow & \text { Tap rap } \\ 235 & \text { AARON } & & \text { No [bath } \\ 236 & \text { MOM } & \rightarrow & \text { [(tub) } \\ 237 & \text { AARON } & & \text { No bath } \\ 238 & \text { MOM } & & \text { Yes bath }\end{array}$




$\begin{array}{lll}239 & \text { AARON } & \text { Or else? (laughing)) } \\ 240 & \text { MOM } & \text { Or else? } \\ 241 & \text { AARON } & \text { Stink ((laughs)) }\end{array}$

Repetition, alliteration, and word play are the building blocks of sequence progressivity in Example $7 \mathrm{~d}$. Both participants contribute the same kinds of moves and uptake, and each displays amusement at those produced by the other.

The last two Examples (7c and d) in particular, illustrate how, in this exchange between Mom and Aaron on the bed, language is set free and allowed to run along the very edges of meaning. Yet the phatic sense of this interactional enterprise appears to get stronger as the two proceed in their on-the-spot invention of ways to go on. The investment of trust, especially by the mother, is very high, and Aaron's moves, particularly in the second half of the episode, demonstrate that the investment is rewarding.

Consider now one last segment from the episode, in which Aaron offers contribution of a sensibly different quality, introducing original wording and taking initiative in topic shift:

Example 7e-Tape \#2 Aaron and Mom on the bed

\begin{tabular}{|c|c|c|}
\hline 250 & MOM & $\begin{array}{l}\text { I don't want you to stink. I want you to smell good. } \\
\text { ((kisses Aaron)) }\end{array}$ \\
\hline 251 & AARON & ((laughs)) I smell good and stinky:: ((laugbing)) \\
\hline 252 & MOM & $\begin{array}{l}\text { I don't want you to stink. I want you to smell good. } \\
\text { Like a flower. }\end{array}$ \\
\hline 253 & AARON & No. not today. I can't be clean ((laughing)) \\
\hline 254 & MOM & Ye::s you ca:n \\
\hline 255 & AARON & Or else? \\
\hline 256 & MOM & $\begin{array}{l}\text { You know what? or else (.) they're gonna send you home } \\
\text { from school. They're gonna say ((closes her nose with hand)) } \\
\text { Aaron you've to go home. you stink too ba:d. }\end{array}$ \\
\hline 257 & AARON & $(($ laughs $))$ stink \\
\hline 258 & MOM & Stinky like Pigpen \\
\hline 259 & AARON & $(($ laugbs $))$ \\
\hline 260 & MOM & You know? \\
\hline 261 & AARON & Pigpen ((laughing)) \\
\hline 262 & MOM & $\begin{array}{l}\text { Pigpen on Peanuts (that kid-) walks and (that) big } \\
\text { dust (fold) [(.) follows him wherever he goes }\end{array}$ \\
\hline 263 & AARON & {$[(($ laughs $))$} \\
\hline 264 & & $(0.5)$ \\
\hline 265 & AARON & Do you remember at Spirited Away? \\
\hline
\end{tabular}




$\begin{array}{lll}266 & \text { MOM } & \text { At Spirited Away? I do. What happened? } \\ 267 & \text { AARON } & \rightarrow \text { (laughs) }) \text { they changed to pi:gs (laughing) }) \\ 268 & \text { MOM } & \text { The parents changed into pi:gs? ((tickling Aaron)) } \\ 269 & \text { AARON } & (\text { (laughs) }) \text { yeah. } \\ 270 & \text { MOM } & {[\text { I ::- }} \\ 271 & \text { AARON } & \rightarrow \text { [The mommy and dad and the boy are pigs } \\ 272 & \text { MOM } & \text { The mommy and the daddy turned into pigs. But the gi:rl, } \\ 273 & \text { AARON } & \text { (it ) the pigs } \\ 274 & \text { MOM } & \text { She didn't turn into pig. She had to rescue her mommy and daddy. }\end{array}$

At the beginning of the excerpt, Aaron and Mom are playfully engaged in another of their conventional exchanges. Therein Aaron expresses a positive stance about a situation that the mother has portrayed as a negative consequence. Here, we see that the child starts inserting novel words into the exchange ("No not today I can't be clean," ln. 254). Shortly after, following mother's elaboration of the "or else" consequences into a school narrative scenario (ln. 256), and her mentioning the Peanuts' character Pigpen (ln. 258), Aaron offers another appropriate novel contribution to the conversation and invites his mother to joint remembering. The topic proposal ("Do you remember at Spirited away?" $\ln .265$ ) ${ }^{12}$ is sequentially adequate, in that it is consistent with the ongoing frame of citing fiction from a common repertoire. It is also significantly complex in that it pursues intersubjectivity not through the immediate resources of repetition and format tying, but through a leap outside the here and now into the shared history of the dyad. Furthermore, it is worth noting how the question "Do you remember... " is a story preface, namely one that announces that the speaker has a story to tell and inquires into the recipient's willingness to listen to it (Schegloff 2007). The mother replies accordingly, with the open question "What happened," which hands the floor back to Aaron without any constraint on the child's production. Then they go on in reconstructing the story together. Aaron's move, thus, differently from appendors and the other second position turns described earlier on, which relied heavily on his interlocutors for providing speech material, is here projecting his own autonomous contribution and steering the interlocutor into warranting him the right and obligation to do so.

Given the amount of recycled speech used by Aaron in the videotaped episodes, the novelty of these contributions, the intimate display of subjectivity that they convey, and the interpersonal sharing they invoke strike the observer as remarkable outcomes of an interactional exchange in which the interactants have taken the risk of going on with each other in exploring and playing with the possibilities of language.

\section{Discussion: The Pursuit of (Inter)Subjectivity}

In this study, we analyzed speech exchanges among a five-year-old child with autism, his parents, and tutor at home, in the course of everyday interactions. We have shown that, 
despite difficulties in producing original contributions to conversation, the child uses progressivity moves that enable his interlocutors to further unfold the communicative exchange. Such moves, which may look repetitive and stereotypical at first sight, use the interlocutor's utterances to generate questions leading to sequences of four or more turns. We have seen that, when his fellow interactants are willing to engage in elaborate replies, Aaron's moves have the potential to engender speech activities that are entertaining for all participants, also allowing for the expression of humor, subjective stances, and abstract knowledge. We have also seen how some of the child's progressivity moves alter the pragmatic trajectory of turns addressed to him, which often are directives or similar acts aimed to instruct and modify his behavior. So, at a closer analysis, it is not just Aaron's utterances, but also the talk addressed to him, which is somewhat repetitive and constrained in content, with the child actually subverting and lending progressivity to such moves.

When, however, the control grip is released, and the participation frame allows for more sharing than controlling, Aaron finds ways of original and wider-span contributions. In the last exchange we have analyzed, the mother creates with her son a context in which even the child's withdrawal does not result in a threat for togetherness, and in which the intersubjective horizon eventually opens up to incorporate narrative and joint remembering. The most relevant features of mother's communication to this end are her keying the interaction in an "as if" mode, and her use of speech play. Both features require trust in Aaron's capacity to participate in the exchange. Such trust transpires in mother's opening slots for her son's contributions and taking those contributions as relevant to the ongoing activity.

Aaron's mother sketches fantasy scenarios around present events-such as the bug flying in the bedroom and Aaron's stepping onto the dog's bed-animating those scenarios with a "pretend" voice, vocal effects, physical play and easy-to-grasp imaginary development of events. Revolving in the "as if" mode is a basic requirement for narrative production, so that exchanges like this are likely to scaffold child's competence in dealing with possible worlds.

Mom is also able to incorporate Aaron's typical progressivity moves, using them as triggers for further invention and play. At the same time, she remains close to her son's competence level, reformulating his utterances, drawing on his very words and sounds for her replies, and engaging in sequences of utter sound play (see, esp., Example 7d). Such poetic means (Jakobson 1960) are critical resources in the interaction with young children (KirshenblattGimblett 1976; Weir 1962), as well as being at the basis of humor and creativity in adult forms of language use (Crystal 1998; Sherzer 2002). Engaging language at this level creates affordances for participation such that the child can act competently and be a source of entertainment for the interactional partner. The quality of intersubjectivity ensured through such means pays off the risk of trust that was initially taken, producing more encompassing and satisfactory exchanges. 
As noted by Bruner and Feldman (1993) and Ochs and Solomon (2004) among others, in autism the motivation to interact is resilient, but competence in contributing to complex and unpredictable speech practices, spanning in time beyond the hic et nunc, is hampered. The language modes we have described are, we contend, promising resources in the interaction with autistic children, in that they draw on the children's motivation for social interchange, exploit their interest and skills with language per se while also creating a nurturing environment for narrative discourse.

If we return to our opening discussion on progressivity and the possible contradiction between the preferences for intersubjectiviy and for progressivity or minimization in conversation, we might here advance the suggestion that the two preferences can flow in the same direction, rather than being always and unavoidably in irreconcilable tension.

Trust is intrinsic to linguistic communication (Garfinkel 1963; Luhmann 1968), but it can be weak when agents want to rein in language liberty (Hanks 1996). When considering the dimension of trust in language, the relation between progressivity and intersubjectivity may be thought of as one of multiplication, or reciprocal enhancement. Trust implies more recognition of an interlocutor's communicative means and rights, and less predictability of her or his behavior. School-like questions, for instance, imply that the questioner has low expectations of the responder and has channeled his or her responses into a narrow range of options; the questioner secures her or his position by implying that he or she possesses the answer. In contrast, speech play is an open format, which, if producing continuity by means such as format tying, is not rigidly determined by complementary relevance such as adjacency pairs. By progressing through parallel verses and side turns and having no predicted termination, speech play and poetic talk see the successive production of "nexts" as creative, with a progressivity that is not obvious but that has to be crafted turn by turn. This is also why speech play, as a genre, offers so much surprise and entertainment.

Interacting with individuals with autism unearths the inherent precariousness and unpredictability of communication. It also reveals the close relationship between acceptance of risk and openness to the other. In this sense sequence progressivity and intersubjectivity are not opposite poles in perpetual epistemological tension, but ethical dimensions of communication that precariously meet and overlap in the ephemeral moments in which someone encounters an other.

LAURA STERPONI is Assistant Professor in Language and Literacy, Society and Culture at the University of California, Berkeley. 


\section{Notes}

Acknowledgments. Funding for the research described in this article was provided by the University of California, Berkeley Committee on Research (CPHS Protocol 2006-2-11, Principal Investigator: Laura Sterponi). We are grateful to the Paxter family for their participation and engagement in this study. We also wish to thank Nancy Bagatell, Olga Solomon, Janet Keller, the anonymous reviewers for their critical advice and insightful comments.

1. A third area of impairment characteristic of autism spectrum disorders is imagination and pretense (Carpenter and Tomasello 2000; Happé 1994; Leslie 1987).

2. This case study is part of a more extended ethnographic and discourse analytic study of the sociocommunicative abilities and difficulties of four children with autism spectrum disorders, aged three to six years (CPHS Protocol 2006-2-11, Principal Investigator: Laura Sterponi).

3. Issues with egocentric and allocentric spatial frameworks evoke Husserl's idea of "trading places" (Platzwechsel) as the basis for intersubjectivity (see Duranti 2009).

4. The principle of minimization can be discerned in a number of conversational phenomena besides sequence progressivity, notably inference mechanisms of membership categorization devices, and the preference for selfrepair and self-initiation of repair over other-initiated repairs.

5. For an analysis of connections between Wittgenstein's philosophy and ethnomethodological tenets see Coulter 1973, 1974; and Heritage 1984.

6. As Schegloff illustrated, the structural organization of conversation provides limited defenses of intersubjectivity, not extending beyond the fourth turn (Schegloff 1992).

7. Heritage pointed out, "[s]ecurity of referential common ground can only be bought by disrupting the progressivity of the sequence in progress. Absolute security of reference is incompatible with progressivity" (Heritage 2007:261).

8. Personal and family names have been changed to protect participants' privacy.

9. Notational conventions employed in the transcribed excerpts include the following:

. Period indicates a falling, or final, intonation contour, not necessarily the end of a sentence.

? Question mark indicates rising intonation, not necessarily a question.

, Comma indicates "continuing” intonation, not necessarily a clause boundary.

$\uparrow \downarrow \quad$ Upward and downward pointing arrows indicate marked rising and falling shifts in intonation.

$\rightarrow \quad$ Right facing arrow indicates lines in the transcript where the phenomenon of interest occurs.

::: Colons indicate stretching of the preceding sound, proportional to the number of colons.

- $\quad$ A hyphen after a word or a part of a word indicates a cut-off or self interruption.

word Underlining indicates some form of stress or emphasis on the underlined item.

WOrd Upper case indicates loudness.

$=\quad$ Equal sign indicate no break or delay between the words thereby connected.

(()) Double parentheses enclose descriptions of conduct.

(word) When all or part of an utterance is in parentheses, this indicates uncertainty on the transcriber's part.

( ) Empty parentheses indicate that something is being said, but no hearing can be achieved.

(1.2) Numbers in parentheses indicate silence in tenths of a second.

(.) A dot in parentheses indicated a "micropause," hearable but not readily measurable; ordinarily less than $2 / 10$ of a second.

[Separate left square brackets, one above the other on two successive lines with utterances by different speakers, indicates a point of overlap onset. 
10. On abstractions and generalizations as closing sequence devices, see Drew and Holt 1995; Edwards 1994; Heritage and Watson 1979; Kitzinger 2000; Schegloff and Sacks 1973.

11. Tickle torture is a playful activity we often observed between the two at moments throughout the day (but not at mealtime).

12. The shift seems to be triggered at lexical level with the transition from Pigpen to the pigs in the animated movie.

\section{References Cited}

American Psychiatric Association

2000 Diagnostic and Statistical Manual of Mental Disorders, 4th edition, text rev. Washington, DC: American Psychiatric Association.

Atkinson, Maxwell J., and John Heritage, eds.

1984 Structures of Social Action: Studies in Conversation Analysis. Cambridge: Cambridge University Press.

Baron-Cohen, Simon

1989a Joint Attention Deficits in Autism: Towards a Cognitive Analysis. Development and Psychopathology 1(3): 185-189.

1989b Perceptual Role-Taking and Protodeclarative Pointing in Autism. British Journal of Developmental Psychology 7(2): 113-127.

Bruner, Jerome, and Carol Feldman

1993 Theories of Mind and the Problem of Autism. In Understanding Other Minds: Perspectives from Autism. Simon Baron-Cohen, Helen Tager-Flusberg, and Donald J. Cohen, eds. Pp. 267-291. Oxford: Oxford University Press.

Carpenter, Malinda, and Michael Tomasello

2000 Joint Attention, Cultural Learning, and Language Acquisition: Implications for Children with Autism. In Autism Spectrum Disorders: A Transactional Developmental Perspective. Amy M. Wetherby and Barry

Coulter, Jeff M. Prizant, eds. Pp. 31-54. Baltimore, MD: Brookes.

1973 Language and the Conceptualization of Meaning. Sociology 7(2): 173-189.

1974 The Ethnomethodological Programme in Contemporary Sociology. Human Context 6(1): 103-122.

Crystal, David

1998 Language Play. Harmondsworth: Penguin.

Deleuze, Gilles

1997[1993] Bartleby; or, the Formula. In Essays Critical and Clinical. Pp. 68-90. Minneapolis: University of Minnesota Press.

Derrida, Jacques

1982 [1972] Signature Event Context. In Margins of Philosophy. Daniel Smith and Michael Greco, trans. Pp. 307-330. Chicago: University of Chicago Press.

Drew, Paul, and Elizabeth Holt

1995 Idiomatic Expressions and their Role in the Organization of Topic Transition in Conversation. In Idioms: Structural and Psychological Perspectives. Martin Everaert,

Erik-Jan van der Linden, André Schenk, and Rob Schreuder, eds. Pp. 117-132. Hillsdale, NJ: Erlbaum.

Duranti, Alessandro

2009 The Relevance of Husserl's Theory to Language Socialization. Journal of Linguistic

Anthropology 19(2): 205-226.

Edwards, Derek

1994 Script Formulations: A Study of Event Descriptions in Conversation. Journal of Language and Social Psychology 13(3): 211-247.

Ford, Cecilia E.

2004 Contingency and Units in Interaction. Discourse Studies 6(1): 27-52.

Gallagher, Shaun

2001 The Practice of Mind: Theory, Simulation or Primary Interaction? Journal of Consciousness Studies 8(57): $83-108$.

2004 Understanding Interpersonal Problems in Autism: Interaction Theory as an Alternative to Theory of Mind. Philosophy, Psychiatry, and Psychology 11(3): 199-217. 
Gallese, Vittorio

2006 Intentional Attunement: A Neurophysiological Perspective on Social Cognition and its Disruption in Autism. Brain Research 1079(1): 15-24.

Garfinkel, Harold

1963 A Conception of, and Experiments with, "Trust” as a Condition of Stable Concerted Actions. In Motivation and Social Interaction. O. J. Harvey, ed. Pp. 187-238. New York: Ronald Press.

1967 Studies in Ethnomethodology. Englewood Cliffs, NJ: Prentice Hall.

Hanks, William

1996 Language and Communicative Practices. Boulder, CO: Westview.

Happé, Francesca

1994 Autism: An Introduction to Psychological Theory. Cambridge, MA: Harvard University Press.

Heritage, John

1984 Garfinkel and Ethnomethodology. Cambridge: Polity.

2007 Intersubjectivity and Progressivity in Person (and Place) Reference. In Person Reference in Interaction: Linguistic, Cultural, and Social Perspectives. Nick J. Enfield and Tanya Stivers, eds. Pp. 255-280.

Cambridge: Cambridge University Press.

Heritage, John, and Rodney D. Watson

1979 Formulations as Conversational Objects. In Everyday Language: Studies in Ethnomethodology. George Psathas, ed. Pp. 123-162. New York: Irvington.

Kanner, Leo

1943 Autistic Disturbances of Affective Contact. Nervous Child 2: 217-250.

Kirschenblatt-Gimblett, Barbara, ed. 1976 Speech Play. Philadelphia: University of Pennsylvania Press.

Kitzinger, Celia

2000 How to Resist an Idiom. Research on Language and Social Interaction 33(2): 121-154.

Itakura, Hiroko

2001 Conversational Dominance and Gender. Amsterdam and Philadelphia: John Benjamins.

Jakobson, Roman

1960 Closing Statements: Linguistics and Poetics. In Style in Language. Thomas A. Sebeok, ed. Pp. 350-377. Cambridge, MA: MIT Press.

Leslie, Alan M.

1987 Pretense and Representation: The Origins of "Theory of Mind." Psychological Review 94(4): 412-426.

Levinson, Stephen C.

1987 Minimization and Conversational Inference. In The Pragmatic Perspective: Proceedings of the

International Conference on Pragmatics at Viareggio. Marcella Papi and Jeff Verschueren, eds. Pp. 61129. Amsterdam: John Benjamins.

Loveland, Katherine A. with Loveland, Katherine A. Susan H. Landry Sheryl O. Hughes Sharon K. Hall, and

Robin E. McEvoy

1988 Speech Acts and the Pragmatic Deficits of Autism. Journal of Speech and Hearing Research 30(4): 593604.

Luhmann, Niklas

1968 Vertrauen. Stuttgart: Lucius and Lucius.

Ochs, Elinor, Tamar Kremer-Sadlik, Karen G. Sirota, and Olga Solomon

2004 Autism and the Social World: An Anthropological Perspective. Discourse Studies 6(2): 147-183.

Ochs, Elinor, and Bambi B. Schieffelin, eds.

1979 Developmental Pragmatics. New York: Academic Press.

Ochs, Elinor, and Olga Solomon

2004 Practical Logic and Autism. In A Companion to Psychological Anthropology: Modernity and

Sacks, Harvey

Psychocultural Change. Conerly Casey and Robert B. Edgerton, eds. Pp. 140-167. Oxford: Blackwell.

1992 Lectures on Conversation. Oxford: Basil Blackwell.

Sacks, Harvey, Emanuel A. Schegloff, and Gail Jefferson

1974 A Simplest Systematics for the Organization of Turn-Taking for Conversation. Language 50: 696-735.

Schegloff, Emanuel A.

1992 Repair after Next Turn: The Last Structurally Provided Defense of Intersubjectivity in Conversation. American Journal of Sociology 97(5): 1295-1345.

1996 Issues of Relevance for Discourse Analysis: Contingency in Action, Interaction and Co-Participant Context. In Computational and Conversational Discourse: Burning Issues, an Interdisciplinary Account. Eduard H. Hovy and Donia Scott, eds. Pp. 3-38. Heidelberg: Springer-Verlag.

2007 Sequence Organization in Interaction, vol. 1: A Primer in Conversation Analysis. Cambridge: Cambridge University Press. 
Schegloff, Emanuel A., and Harvey Sacks

1973 Opening up Closings. Semiotica 8(4): 289-327.

Schutz, Alfred

1966 The Problem of Transcendental Intersubjectivity in Husserl. In Collected Papers, vol. 3: Studies in

Sherzer, Joel Phenomenological Philosophy. Pp. 51-83. The Hague: Martinus Nijhoff.

2002 Speech Play and Verbal Art. Austin: University of Texas Press.

Shotter, John

1996 "Now I can Go On": Wittgenstein and our Embodied Embeddedness in the "Hurly-Burly" of Life.

Human Studies 19(4): 385-407.

Snow, Catherine

1986 Conversations with Children. In Language Acquisition. Paul Fletcher and Michael Garman, eds. Pp. 363375. Cambridge: Cambridge University Press.

Trevarthen, Colwyn, and Kenneth J. Aiken

2001 Infant Intersubjectivity: Research, Theory and Clinical Applications. Journal of Child Psychology and Psychiatry 42(1): 3-48.

Weir, Ruth

1962 Language in the Crib. The Hague: Mouton.

Wittgenstein, Ludwig

1958 Philosophical Investigations. Oxford: Blackwell.

Wootton, Anthony

1997 Interaction and the Development of Mind. Cambridge: Cambridge University Press. 